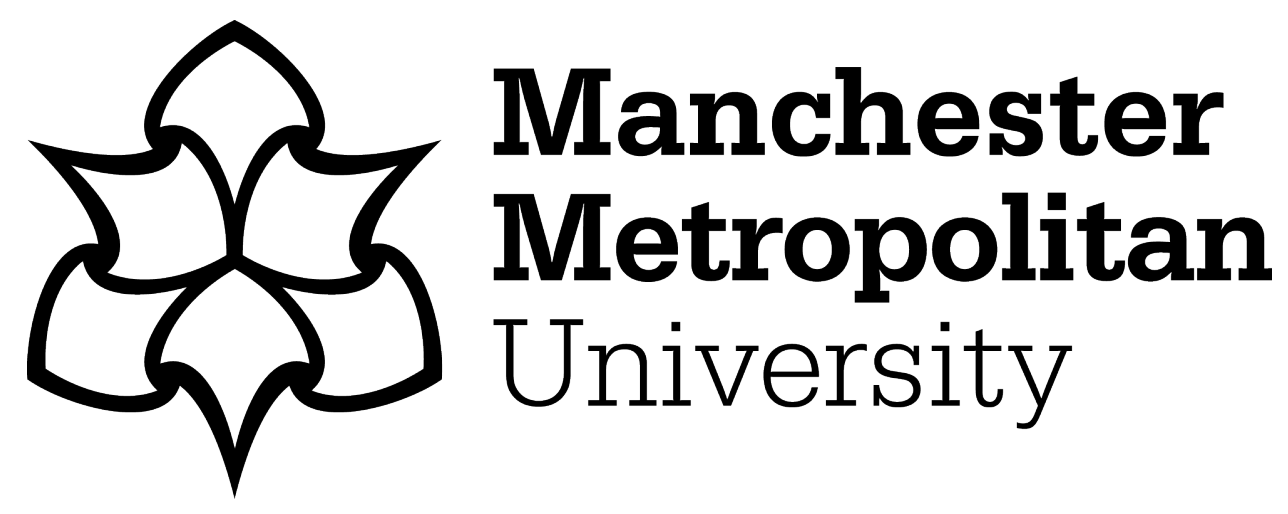

McGuire, Brendon, Cooper, William and Park, Michael (2006) Pastoral care, spirituality and physical education. Pastoral care in education, 24 (4). pp. 13-19. ISSN 1468-0122

Downloaded from: https://e-space.mmu.ac.uk/92662/

Version: Accepted Version

Publisher: Taylor and Francis

DOI: https://doi.org/10.1111/j.1468-0122.2006.00385.x

Please cite the published version 


\title{
Pastoral Care, Spirituality and Physical Education
}

\begin{abstract}
Within the sphere of Physical Education (PE), many observers (Shields and Bredemeier, 1995; Green, 2003; Capel, 2003,) have identified PE staff as having a special empathy for children's pastoral care needs and the development of Personal, Social, and Health Education (PSHE). Such factors as the varied situations and venues in which the subject is delivered, including off-campus and extra curricular activities, perhaps leads interested staff into work that locks into the welfare and personal development needs of children. Accordingly, one of the more interesting challenges posed by National Curriculum Physical Education (NCPE) is that it requires the teacher to address the spiritual development of the pupil; this obligation is made clear through the Spiritual, Moral, Social and Cultural (SMSC) elements of the subject (DfEE and QCA, 1999a).
\end{abstract}

This paper focuses attention on the merging of this separate spiritual dimension with the other three concepts. Whilst the moral, social and cultural elements of SMSC are recognised components of $\mathrm{PE}$ participation, the grouping raises the question of whether PE teachers can develop children's spiritual growth. This paper argues that such a pathway may be possible but that at present there is considerable confusion related to the challenge.

Keywords: physical education; pastoral care; spiritual, moral, social, cultural. 


\section{Introduction}

At the time of writing, issues relating to spirituality, citizenship, ethnicity, asylum seekers, 'religious fanaticism', and faith schools make daily headlines in the media; it seems inevitable therefore, and indeed desirable, that educators would want to broach these sensitive subjects with young people. Cooper (2004) cites an example of this recent development when she says:

Numerous violent events associated with schools such as the Dunblane Massacre (13 March 1996), precipitated moral and humanitarian concern and led people to question how we might improve the moral state of the nation.

(Cooper, 2004, p.13)

Understandably, the government wishes to continue to promote such features as cultural tolerance, knowledge of religious beliefs and exploration of what constitutes a 'good citizen' with renewed vigour within our complex, post 9/11 world. The government has made clear its aim of adding to this legal structure a strong educational and social underpinning to produce thoughtful, responsive and responsible citizens. This is highlighted in the Primary National Strategy, where it states:

Being able to empathize involves understanding others; anticipating and predicting their lively thoughts and feelings and perceptions. It involves seeing ...things from another point of view and modifying one's own response, if appropriate, in the light of this understanding...to reflect on spiritual, moral, social and cultural issues, using imagination to understand other people's experiences.

(DfES, 2004, p.50) 
The National Curriculum (NC) for teachers in England and Wales also states unequivocally that pupils' spiritual development must be catered for in each and every subject through the SMSC framework:

All National Curriculum subjects provide opportunity to promote pupils' spiritual, moral, social and cultural development...Pupils' spiritual development involves the growth of their sense of self, their unique potential, their understanding of their strengths, and their will to achieve. As their curiosity about themselves and their place in the world increases, they try to answer for themselves some of life's fundamental questions. They develop the knowledge, skills, understanding, qualities and attitudes they need to foster their own inner and non-material well-being.

(DfEE and QCA 1999b, p.20)

At present, the foreword to NCPE (DfEE and QCA, 1999a) stays conservatively within the bounds of the moral, social and cultural elements of the umbrella term; elsewhere in the document there is limited advice about how the teacher of physical education might promote this separate spiritual development:

Spiritual development: through helping pupils gain a sense of achievement and develop positive attitudes towards themselves.

(DfEE and QCA,1999a, p8)

NCPE suggests that spirituality is not linked to organised religion at all, that it is an entirely secular notion, most easily accommodated within the wider SMSC context and talks of personal qualities, skills and attitudes. However, whether an individual 
can in fact be 'spiritual' without making any reference to an organised religion, is an important question which others have previously raised:

Some teachers express exasperation at the absence of any common definition of the term and its adoption by secular groups to the exclusion of any religious elements, while others cannot accept that the spiritual dimension might exist outside religion.

(Gill, 2000, p112)

As currently presented in NCPE, consideration of pupils' religious beliefs is not related to our spiritual aspirations for them, despite the fact that many dictionary definitions of the term 'spiritual' do link it to organised religion (Bloomsbury, 2004).

\section{The Positioning of Spirituality within the SMSC Grouping}

Spirituality is positioned within a grouping, where even the other more familiar concepts have not always brought consensus of opinion. For instance, the issue of promoting moral values through physical education is not necessarily being fully achieved in the eyes of some observers, who doubt claims that such activities as team games automatically bring about these desirable developments:

When direct teaching strategies are employed in relation to the teaching of moral values, teachers are unclear about how to implement them effectively in order to achieve moral values.

Theoduoulides (2003, p.141)

In an attempt to clarify terms, Carr defines values as, '....generally matters of practical aspiration which require for their true appreciation and acquisition a large measure of commitment, devotion and engagement.' (Carr, 1999, p35). 
Sheridan (2003) supports Theoduoulides' (2003) argument by saying that it is unclear both in sport and life generally what an assumption such as 'fair play' (a term frequently referred to by politicians in relation to wider societal issues during the runup to the General Election, 2005) actually means. In particular, ' ...it is not clear what precisely it refers to, why it is valued, what ethical principles, if any, it is grounded upon and what kind of good it involves' (Sheridan, 2003, p.163). Halstead and McLaughlin (1999) support this position:

Moral education is high on the agenda of most western societies, but the contemporary climate of moral confusion and sometimes panic is not necessarily conducive to considered judgments about what teachers and schools should be doing in this area....There is no shortage of new initiatives and strategies in many parts of the world, but sometimes these simply add to the confusion.

(Halstead and McLaughlin, 1999, p1).

Despite Sheridan's (2003) reservations however, elsewhere there is significant literature relating to important concepts such as fair play and morality issues within sport (see Jones and McNamee, 2000). Hellison and Templin (1991) state that, 'Fair play, cooperation, competition, and other issues are certain to be part of the physical education experience' (p.102). They argue that the most effective learning will occur when PE teachers are self reflective, showing 'concern and caring...teaching by example......creativity (and) a playful spirit' (p.162). Hellison (1995) adds that, 'A playful spirit involves lots of things, including being upbeat and enthusiastic (but only genuinely so), having fun with the kids and celebrating...' (Hellison (1995, p59). Through such interactions he claims that these, 'tiny victories carry some weight' Hellison (1995, p.94); that shared meaningful experiences between the pupil and the 
physical educator can lead towards lives being richer and more fulfilled. However, the steady shift away from such an approach towards a more mechanistic, prescribed curriculum has not gone unnoticed:

The pervasive use of the language of competence, skills and standards to describe educational objectives and the professional preparation of teachers has also served to undermine a more explicit approach to values education.

(Wylie, 2005, p14)

Within NCPE, the text reads as if the PE profession is fairly clear about where the moral, social and cultural elements fit into the subject. And, although definitive views may not exist concerning the value of each, we can perhaps see, in a practical sense, how physical education contributes to pupils' development in these spheres. For instance, in terms of fostering pupils' moral development, the NCPE recommendations (DfEE and QCA, 1999a) point to the desired aims of fair play and sporting behaviour. We might then conclude that schools, generally, already encourage such moral development to a greater or lesser extent through their work, believing that:

A morally educated sportsperson (good person) will try to react to the kind of conflict situation not only in accordance with a specific principle (e.g. fair play) but also her/his certain good dispositions (e.g. respect for others and sympathy) in which the decision is made at a critical level of moral thinking.

(Hsu, 2004, p150)

Social development, one might claim, is largely achieved through cooperation, teamwork and collaboration. It is also fairly plausible to accept how cultural 
development can be assisted through experiencing say, folk dances or games from other cultures. Kabaddi, for instance, taught as a team game may help children to understand the cultural background of Asian heritage pupils in multicultural schools, whilst enjoying an exciting activity.

However, it would seem that provision to encourage growth of the spiritual dimension within NCPE is, in comparison to the other three components, very poorly detailed. At present the concept sits uneasily and unhelpfully (from a practical perspective) within its present framework, leaving one to wonder whether what is claimed to be of the spiritual realm is nothing more than 'good' moral, social and cultural development: progress, one might argue, that we have always sought to achieve in the subject. However, Reid (1997) warns of the dangers of such confusion since the related issues can often unhelpfully dictate policy.

\section{SMSC Development Within an Assessment-Driven Curriculum}

For some schools though, the first time they have had cause to consider this separate issue of spirituality (what it is and how to teach it) is to have it pointed out to them as criticism in an OFSTED inspection:

After an OFSTED inspection 18 months ago, the PE department in which one of the writers (Theodoulides) taught was informed that PE staff did not do enough to promote pupils' spiritual development. The thought that they could promote spiritual development was not one that had previously been embraced by the teaching team.

(Theodoulides and Armour, 2001,p7) 
The same authors also make the telling point that the Education Reform Act (DfES, 1988) requires schools to promote children's spiritual development, referring to such an OFSTED report as a 'forceful reminder' that such work is actually obligatory (Theodoulides and Armour, 2001, p.7). Of course, one suspects that Theodoulides' personal experience is not an isolated example; anecdotal evidence suggests that there are some schools which choose to ignore such an obligation. Rather than address the issue, they may instead be prepared to accept the appropriate inspection criticism, when it arrives, secure in the knowledge that other schools too may be taking this stance.

In today's assessment-driven curriculum, spiritual growth may also be seen as unimportant because it cannot be assessed. However, it is argued that:

It is neither possible nor desirable to try to assess pupils' spiritual progress. This part of ourselves is intensely personal - a part of our sense of who we are, that we may or may not wish to share with others. We are not assessing spiritual development, but we should ensure that we facilitate it.

(Vyas, 2002 p.30)

\section{Spiritual and Religious Influences in the Curriculum}

To clarify such matters at primary schools level, an influential paper was published by the Christian Education Movement (Mackley and Draycott, 2000) stating five propositions, regarding active learning strategies, which could be used across the NC whilst focusing on the spiritual aspects of the curriculum. These were: 
1. The whole purpose of education is to foster the personal growth of children - to help them realise their human potential

2. The whole curriculum should support this aim

3. Spiritual and moral development relates particularly to this aim and should pervade the whole curriculum

4. Religious education has a particular role within spiritual and moral education

5. In promoting personal growth the processes of education are as important as the content.

(Mackley and Draycott, 2000, p2)

The paper encourages professionals to utilise teaching strategies which would help pupils to learn about themselves, in each of the curriculum areas including physical education. Colleagues from the RE department would give support in offering learning processes which were likely to promote self-discovery and develop pupils' capacity to relate to their peers. The National Curriculum too, is unequivocal in its drive to promote, predominantly, the positive aspects of human personality as a means to fostering spiritual development. Focusing on spiritual development, teachers are advised that the school curriculum should:

- pass on enduring values

- promote children's self esteem and emotional well-being

- help them form and maintain worthwhile and satisfying relationships based on respect for themselves and for others, at home, school, work and in the community

- develop ability to relate to others and work for the common good 
- enable children to respond positively to opportunities, challenges and responsibilities, to manage risk and to cope with change and adversity

- enable them to appreciate the relevance of their achievement in life and society outside of school.

(DfEE and QCA 1999b, p.20)

Of course, PE has often been associated with the notion of character development; and the belief that sport builds good character, has sometimes been accepted as mainstream thought and promoted by various religions (Coakley 2001). However, in our increasingly secular UK society, such bold linking of spirituality and sport (within the context of the education of children) would perhaps now be the sole preserve of faith schools.

\section{Muslim Pupils and Physical Education}

Historically, issues of spirituality and religion as they relate to physical education are not new, nor are they linked to any one religion only. Islam, for instance, has already presented challenges and opportunities for teachers of physical education who have had to evaluate how they should offer the subject, while respecting the cultural and spiritual needs of the child. Muslim pupils have for many years endeavoured to participate in physical education while maintaining their religious customs (see Carroll and Hollinshead, 1993; Fleming,1993; McGuire and Collins,1998) and at times this participation has placed them in difficult circumstances, seemingly at odds with the demands of the subject. Indeed, over the last four decades, the whole issue of Muslim pupils' participation in PE has had a certain amount of cultural and religious/spiritual 'baggage' attached to it (see DES, 1985). 
While multicultural/antiracist policy development was making its ponderous way through UK schools in the 1980's, in the light of the so-called 'race riots' which preceded the legislation (see Verma and Bagley, 1984), Physical Education was pinpointed as being an area of concern for parents of Muslim pupils (DES, 1985). Often these problems were related to 'practicalities', when the fundamental requirements of religious participation were contrary to the existing ways of delivering the subject (see McGuire and Collins, 1998). For instance, many schools have, traditionally, had very rigid policies on showering, although perhaps far less so in recent times. Since most of the UK's school-changing rooms have communal showers, sometimes very primitive, and little provision for privacy generally, this scenario is immediately contrary to the needs of Muslims (female and male) who are required by their religion not to appear naked in front of others. Thus a child's religious/spiritual integrity (whether they see their faith and themselves as being valued) could actually be brought into question and compromised, simply by participation in standard practices that underpin delivery of the subject (see Carroll and Hollinshead, 1993). Dress is another necessary consideration. If the school policy says, strictly, that girls must wear a short skirt and sleeveless top for PE, this is again contrary to religious expectations for many adolescent girls from Muslim families, who would regard such attire as being immodest. Fasting, as a religious requirement, and subsequent heavy physical exertion, represents yet another very obvious factor that school PE departments have needed to consider from a health perspective (see McGuire, 1993).

Indeed, it might be fair to say that many Muslim schoolchildren, from earlier less educationally enlightened days, have frequently been 'caught between' competing 
cultures and must have suffered very considerably as a result (see Taylor, 1984). Thankfully now, research suggests that much better provision is made for Muslim pupils in physical education (Fleming, 1993; McGuire and Collins, 1998) and through it we might conclude that their spiritual and religious growth is now being encouraged much more appropriately than it was in decades gone by. Indeed, perhaps it is the case that when we are bold enough to confront these sensitive and important issues of cultural and religious requirements (fasting, prayer, diet, dress etc) we come closer to answering the question of what the development of spiritual growth actually is, and whether or not physical education can assist it.

In a broadly similar fashion, it may be argued that a teacher possessing good pastoral care skills, who helps a Sikh boy to tie back his hair in physical education lessons, is demonstrating that (s)he values the child's religious customs. Equally, reacting empathetically to different religions' attitudes towards such issues as menstruation, contraception, alcohol and drugs may also be seen as examples of teachers respecting pupils' spirituality.

\section{What Else is Possible?}

One might ask whether faith schools (or, 'schools with a religious character') deliver spirituality in physical education significantly differently to non-faith schools. Myers (1997) suggests that faith, as understood through traditional religions, incorporates

spirituality, especially the 'spirituality of caring' (Myers,1997,p.105). She argues further, that a child's faith can develop over time, through sharing concrete experiences with those they communicate with on a daily basis. She describes this bonding of individuals as involving, 'shared centres of value and power', claiming 
that these scenarios promote trust and loyalty between members of the centres; a centre, she argues, could be, 'God, the Muslim religion, Manchester United or a school.' (Myers, 1997, p103).

One could develop this thinking to suggest that a faith school has a strong, attractive ethos that permeates the school community and that all members (parents, teachers and children) are experiencing this shared centre of value and power. The spirituality of caring is then said to be present and acts as a dynamic. This too was highlighted by Cush (2003) when questioning whether faith schools should receive state funding (p10). If faith schools do possess these shared centres of value and power, then it could be argued that they are effectively nurturing spiritual development in children; that spirituality is being taken onto the games field or into the sports centre and being used as a positive by individuals and the team alike.

Blaycock (2004) gives many examples of the use of visual aids to assist the PE teacher, in transferring ideas into the curriculum. For example, by reflecting on stars in the sky, in say a form-time lesson, pupils could fill in each point of the star with an example of what makes a chosen leader (Beckham, Holmes, Redgrave, GreyThompson etc). This could then be discussed in the context of a PE lesson to reinforce the theme. In this way the PE teacher would then be enhancing whole school policy regarding the requirements of spirituality and endorsing the philosophy that spirituality is about the whole person, as a result of a series of experiences, shared across the curriculum. 
As Stone (1997) states: “in developing children's spiritual awareness, our starting point is children's own experience" (p.8). She argues that teachers should build on skills which pupils bring with them in order to develop a supportive and constructive ethos and then provide time within the sessions to allow for reflection; be it quietly and individually, or spoken in a group situation in order to appreciate the success or otherwise of that series of events during the course of the lesson. Dawson (2002) adheres to this philosophy when he argues that any curriculum subject can utilise spiritual experience in a performance in order to facilitate learning in pupils. He promotes the need for teachers to identify with youth cultural influences such as skating, skiing and surfing because these are seen as being 'cool' in the eyes of teenagers. Surfing is regarded as being cool because it is an activity which involves passion, awe and danger. Every wave is unique and so a different experience awaits the rider when they drop off the next roller:

By explicitly associating the learning process in the RE classroom with the culture of surfing; with its need for self-discipline, etiquette, practice, effort, risk, taking and undiluted pleasure, a department can engineer a learning ethos that stimulates and affirms the emergent theologies of its pupils.

(Dawson, 2002, p.10)

Significantly perhaps for Physical Education, Roberts (2000) suggests that the four areas of SMSC should be separated and that each curriculum area should provide an example of an activity for every year group for each of the four areas. In that way, it is argued, every teacher in the school ought to contribute to the development of spirituality and in so doing should be reflecting on how her/his teaching style helps or hinders the pupils' experiences. It is challenges like this which all PE teachers face. 
Can we find subject matter/issues that could contribute not only to a pupil's traditional physical education progress but also to her/his spiritual development?

Bigger and Brown (1999) provide a lucid and analytical account of what the term 'spirituality' equates to in primary education today, with contributors to their book illustrating how each curriculum area can in turn address spirituality in terms of teaching and satisfying OFSTED inspections. In her chapter on Physical Education, Gray (1999) highlights the value of outdoor and adventurous activities for children as not only experiencing the vulnerability of working in a hostile environment, but stressing how that can awaken the spiritual side of each individual, through the realisation of the enormity of the elements which they pitch themselves against. Gray continues:

Spirituality deals with contemplation about ourselves. It is the development of our inner self. PE, if only seen as recreation or keeping fit, misses out on vital elements of physical development. Confidence and competence are linked; physical and emotional development goes hand in hand.

(Gray, 1999, p151)

She then argues how attainable targets set for all pupils can provide a sense of fulfillment by personal achievement, thus contributing to each pupil's spiritual growth. Focus is also given to the importance of a positive teaching style and a constructive learning environment in order to foster this spiritual growth in individuals. This responsibility is directed very clearly at the teacher and it is a common theme among contributors to this debate: 
Spirituality ....is not about the content of your teaching but about the approach you take. It is about your attitude and how you teach.

(Hoodless et al, 2003, p164)

\section{Would The Study of the Body Be Appropriate?}

Could the study of the body, for example, be viewed more imaginatively and within a spiritual sense, beyond the realms of a respiratory system and muscular functioning? The Holy Books of most mainstream religions make strong reference to our physical bodies and how we should come to regard them. Also, there is a plethora of accompanying texts relating to spiritual dimensions concerning our earthly bodies. It is claimed that:

In the organization of our atoms, proteins, and integrated systems is the evidence that we were created with a marvelous, miraculous design intended not only to define but also to promote and prolong our physical existence on the earth, according to a divine plan.

(Gills, 2004, p35)

Perhaps, when causing pupils to think about how their bodies work (something we do now as routine within the subject of physical education through Health Related Exercise) we could also encourage them to consider how such a design came about. Whether responses were aligned to religious or evolutionary theories it might be fair to state that such discussion would be interesting and useful in prompting consideration of the '...non-material well being' element which NCPE aims to illuminate in lessons (DfEE and QCA, 1999b, p20).

Indeed, extending this theme, it is perhaps imperative that, as physical educators, we do not allow children to pass through our programmes without ever encouraging them 
to consider the design of their own bodies in such spiritual terms. This could be an informal discussion during a cool-down or prompted by a special moment, perhaps having reached the summit during a group hill walk, or being pitted against the elements during water sport. Such moments may be rare and precious, serving to make children think and wonder about their place in the universe, even involving feelings of awe. They can be occasions that both pupils and educators remember long after the event, invoking a 'sense of wonder and unfathomable mystery' (HenzellThomas, 2004 , p.42) which is central to discussions concerning spirituality.

\section{Conclusion}

To conclude, it is interesting to note that, despite having far fewer PE specialists delivering the subject, current examples of pioneering work relating to spirituality are perhaps currently more common in primary rather than secondary education. Faith schools also offer useful insights into the issue.

Similarly, there may be many different viewpoints among teachers of physical education about how the concept should actually be handled. As it stands, we might conclude that there is a heavy 'personal development' influence (attitudes, self esteem raising etc.) and perhaps a mere reinforcement of moral, social and cultural themes. Of course, many may say that this is exactly the right focus since it is a natural process, linked to support of PSHE work; something we have always done through the subject. We might also conclude that, at present, if there is any significant linking of the spiritual to the religious then it is primarily influenced by Christianity through the C.E.M. (Mackley and Draycott, 2000). As such, some might see this as appropriate within a country with a long Christian heritage, while others could think it 
unrepresentative of our present, multi-faith society. However, whatever position a particular school may take, it must be acknowledged that spiritual development has to be addressed (DfEE and QCA, 1999b) and that we should then be doing it more insightfully and more rigorously than we do at present.

Interestingly, no reference is made to spiritual development in the document of professional standards for Qualified Teacher Status (QTS) published as recently as 2003 (TTA, 2003). These are the standards which trainee teachers must meet before they can be awarded QTS. This seems hard to comprehend, given that the existing legal and educational frameworks do focus on the concept. Reflective learning is the focus for today's ITT courses. In response to the 2003 OFSTED inspection framework, there is a much greater emphasis now placed upon self-evaluation and review, as a basis for assessing school performance. Reflection on spirituality should surely be a central feature of this work. It is imperative that while teachers of physical education strive to improve practical performance and the grades of children, this should not be achieved at the expense of consideration of children's spiritual growth. Indeed, in the current social climate with issues of faith and spiritual beliefs very much to the fore, such a topic perhaps takes on a more significant role and there is a heightened sense of urgency to see it addressed. 
References

BIGGER, S. and BROWN, E. (1999) Spiritual, Moral, Social and Cultural Education: Exploring Values in the Curriculum. London: Fulton.

BLAYCOCK, L. (2004) Tears, Leaves, Question Marks and Lightbulbs, RE Today, $22(1), \mathrm{pp} 18-19$

BLOOMSBURY (2004) Encarta World English Dictionary. London: Bloomsbury.

CAPEL, S. (2003) Learning to Teach Physical Education in the Secondary School. London:Routledge.

CARR, D. (1999) Cross Questions and Crooked Answers: Contemporary Problems of Moral Education, in J.M. Halstead and T.H. McLaughlin (eds.), Education in Morality. London: Routledge.

CARROLl, B. and HOLlinsheAD, G. (1993) Ethnicity and Conflict in Physical Education. British Educational Journal, 19 (1), pp59-76.

COAKLEY, J.J. (2001) Sport in Society: Issues and Controversies. Boston: McGraw Hill.

COOPER, B. (2004) Empathy, Interaction and Caring; Teachers' Roles in a Constrained Environment, Pastoral Care in Education, 22 (3), pp12-21. 
CUSH, P. (2003) Should the State Fund 'Schools with a Religious Character'?

The Journal for the Professional Council for Religious Education, 25:2, pp10-15.

DAWSON, A. (2002) The Spirituality of Surfing, RE Today,19 (3) p10.

DEPARTMENT OF EDUCATION AND SCIENCE (1985) Education for All: The Report of the Committee of Inquiry Into the Education of Children from Ethnic Minority Groups. London: HMSO.

DEPARTMENT FOR EDUCATION AND SCIENCE (1988) The Education Reform Act. London: HMSO.

DEPARTMENT FOR EDUCATION AND THE ENVIRONMENT AND THE QUALIFICATIONS CURRICULUM AUTHORITY (1999a) Physical Education National Curriculum for England. London: HMSO.

DEPARTMENT FOR EDUCATION AND THE ENVIRONMENT AND THE QUALIFICATIONS CURRICULUM AUTHORITY (1999b) National Curriculum for England. London: HMSO.

DEPARTMENT FOR EDUCATION AND SKILLS (2004) Primary National Learning Strategy: Learning and Teaching in the Primary Years. London: HMSO.

FLEMING, S. (1993) Sport, Schooling and Asian Male Youth Culture, Sociology Revue, September, pp29-33. 
GILL, J. (2000) 'The Contribution of the Act of Collective Worship to Spiritual and Moral Development,' in R. Best (ed.), Education for Spiritual, Moral, Social and Cultural Development. London: Continuum.

GILLS, J. P. (2004) God's Prescription for Healing. Florida: Siloam.

GRAY, J. (1999) Physical Education, in S. Bigger and E. Brown, E. (eds.) Spiritual, Moral, Social and Cultural Values in the Curriculum. London: Fulton.

GREEN, K. (2003) Physical Education Teachers on Physical Education, a Sociological Study of Philosophies and Ideologies. Chester: Chester Academic Press.

HALSTEAD, J.M. and MCLAUGHLIN, T.H. (1999) Education in Morality. London: Routledge.

HELLISON, D.R. (1995) Teaching Responsibility Through Physical Activity. Illinois: Human Kinetics.

HELLISON, D.R. and TEMPLIN, T.J. (1991) A Reflective Approach to Teaching Physical Education. Illinois: Human Kinetics.

HENZELL-THOMAS, J. (2004) Passing Between the Clashing Rocks: the Heroic Quest for a Common and Inclusive Identity, Pastoral Care in Education, 22 (3), pp35-43. 
HOODLESS, P., BERMINGHAM, S., MCCREERY, E., and BOWEN, P. (2003) Teaching Humanities in Primary Schools . Exeter: Learning Matters Ltd..

HSU, L. (2004) Moral Thinking, Sport Rules and Education, Sport, Education and Society, 9 (1), pp143-154.

JONES, C. and McNamee, M. (2000) Moral Reasoning, Moral Action and the Moral Atmosphere of Sport, Sport Education and Society, 5 (2) pp131-146.

MACKLEY, J. and DRAYCOTT, P. (2000) A - Z : Active Learning Strategies to Support Spiritual and Moral Development. Derby: Christian Education Movement.

MIRACLE and REES (1994) Lessons of the Locker Room. New York: Prometheus.

McGUIRE, B. J. (1993) The Participation of Muslim Schoolchildren in Sport. Sports Teacher, Spring, pp9-12.

McGUIRE, B.J. and COLLINS, D. (1998) Sport, Ethnicity and Racism: the Experience of Asian Heritage Boys, Sport, Education and Society, 3 (1), pp79-88.

MYERS, B.K. (1997) Young Children and Spirituality. London: Routledge.

REID, H. (1997) Value Pluralism and Physical Education, European Journal of Physical Education, 3, (1) pp6-20. 
ROBERTS, J. (2000) Practical Ways for Developing SMSC Across the Curriculum, in, R. Best, Education for Spiritual, Moral, Social and Cultural Development. London: Cassell.

SHERIDAN, H. (2003) Conceptualising Fair Play: A Review of the Literature. European Physical Education Review, 9, (2) pp163-181.

SHIELDS, D.L.L. and BREDEMEIER, B.J.L. (1995) Character Development and Physical Activity. Illinois: Human Kinetics.

STONE, M. (1997) Don't Just Do Something - Sit There. Norwich: Religious and Moral Education Press.

TAYLOR, M. (1984) Caught Between. London: Nelson.

TEACHER TRAINING AGENCY (2003) Qualifying to Teach - Handbook of Guidance. London: Teacher Training Agency.

THEODUOULIDES, A. (2003) 'I Would Never Personally Tell Anyone to Break the Rules, But You Can Bend Them': Teaching Moral Values Through Team Games, European Journal of Physical Education, 8 (4) pp141-160. 
THEODOUliDES, A. and ARMOUR, K. M. ( 2001) Personal, Social and Moral Development Through Team Games: Some Critical Questions, European Journal of Physical Education, 7 (1), pp5-23.

VERMA, G.K. and BAGLEY, C. (1984) Race Relations and Cultural Difference. Kent: Croon Helm.

VYAS, N. (2002) How Do We Recognise and Facilitate Spiritual Growth? RE Today, 19 (3) p30.

WYLIE, K. (2005) The Moral Dimension of Personal and Social Education. Pastoral Care in Education. 23 (3), pp12-18. 